University of Wollongong

Research Online

Faculty of Engineering - Papers (Archive)

Faculty of Engineering and Information

Sciences

$1-1-2012$

\title{
Enhancement of the electrochemical capacitance of TiO2 nanotube arrays through controlled phase transformation of anatase to rutile
}

\author{
Maryam Salari \\ University of Wollongong, msalari@uow.edu.au \\ Seyed Hamed Aboutalebi \\ University of Wollongong, sha942@uowmail.edu.au \\ Alfred T. Chidembo \\ University of Wollongong, atc987@uowmail.edu.au \\ Ivan P. Nevirkovets \\ University Of Wollongong, ivann@uow.edu.au \\ Konstantin Konstantinov \\ University of Wollongong, konstan@uow.edu.au
}

See next page for additional authors

Follow this and additional works at: https://ro.uow.edu.au/engpapers

Part of the Engineering Commons

https://ro.uow.edu.au/engpapers/5231

\section{Recommended Citation}

Salari, Maryam; Aboutalebi, Seyed Hamed; Chidembo, Alfred T.; Nevirkovets, Ivan P.; Konstantinov, Konstantin; and Liu, Hua-Kun: Enhancement of the electrochemical capacitance of TiO2 nanotube arrays through controlled phase transformation of anatase to rutile 2012, 4770-4779.

https://ro.uow.edu.au/engpapers/5231 


\section{Authors}

Maryam Salari, Seyed Hamed Aboutalebi, Alfred T. Chidembo, Ivan P. Nevirkovets, Konstantin Konstantinov, and Hua-Kun Liu 


\title{
Enhancement of the electrochemical capacitance of $\mathrm{TiO}_{2}$ nanotube arrays through controlled phase transformation of anatase to rutile
}

\author{
Maryam Salari,* Seyed Hamed Aboutalebi, Alfred T. Chidembo, \\ Ivan P. Nevirkovets, Konstantin Konstantinov and Hua Kun Liu
}

Received 10th February 2012, Accepted 14th February 2012

DOI: $10.1039 / \mathrm{c} 2 \mathrm{cp} 40410 \mathrm{a}$

\begin{abstract}
Here, we report the fabrication of self-organized titania $\left(\mathrm{TiO}_{2}\right)$ nanotube array supercapacitor electrodes through controlled phase transformation of $\mathrm{TiO}_{2}$, with aerial capacitances as high as $2.6 \mathrm{mF} \mathrm{cm}^{-2}$, which far exceeds the values so far reported in the literature. The role of phase transformation in the electrochemical charge-discharge behaviour of nanocrystalline $\mathrm{TiO}_{2}$ nanotubes is investigated and discussed in detail. The ease of synthesis and the exceptional electrochemical properties make these nanotube arrays an alternative candidate for use in energy storage devices.
\end{abstract}

\section{Introduction}

The many applications of high capacity energy storage devices have resulted in an increasing interest in both discovering new materials of choice for energy storage devices and the introduction of new methods to engineer previously known materials. Therefore, many research efforts have been directed toward developing simple, effective, and environmentally-friendly methods for the production of the next generation of supercapacitors, which can be employed in a wide range of devices, such as flexible electronics, radio-frequency identification devices (RFID) and wearable devices. ${ }^{1-5}$ Although remarkable progress has been made in the production of electrochemical capacitors, there are much neglected in terms of improving the properties of the previously known materials. Nevertheless, production of high performance and cost-effective materials is still a challenge.

Among non-faradic supercapacitors (electric double layer capacitors (EDLCs)), much interest has been focused on carbon based materials, resulting in the abandonment of the other types of conventional EDLCs. However, many of the processes developed for the production of carbon based EDLCs engage environmentally unfriendly chemicals and elaborate procedures. Furthermore, the high cost of carbon nanotubes and graphene might render them unfeasible for practical everyday use applications. The search for alternative suitable materials has led to a renewed interest in titanium dioxide $\left(\mathrm{TiO}_{2}\right)$ based supercapacitors. $\mathrm{TiO}_{2}$, as a highly functional material with many interesting applications in diverse areas, including energy storage, ${ }^{6,7}$ medicine,${ }^{8-10}$ photovoltaic, ${ }^{11-13}$

Institute for Superconducting and Electronic Materials, ARC Centre for Electromaterials Science, University of Wollongong, Wollongong, NSW 2500, Australia.E-mail: ms591@uowmail.edu.au;

Fax: +61 (2)42215731; Tel: +61 (2)42981470 sensors, ${ }^{14}$ solar cells, ${ }^{15}$ etc., has been considered as a hotspot for many applications. Recently, our group has developed new engineered energy devices based on oxygen depleted, highlyordered, self-organized titania nanotubes synthesized via anodic oxidation of titanium foil to overcome the high electrical resistivity of bare titania to meet the requirements for higher specific capacitance applications. For many applications, the crystal phase structure and the size of the particles are the most crucial parameters to alter the surface area and properties of titania, ${ }^{16,17}$ resulting in different electrochemical properties. As-synthesized $\mathrm{TiO}_{2}$ is usually amorphous, which limits its application in many fields. Therefore, to apply $\mathrm{TiO}_{2}$ in practice, the resultant material has to be annealed at relatively high temperatures. ${ }^{18}$ In contrast with photocatalytic applications, in which it has been reported that a mixture of anatase and rutile phases is more efficient, ${ }^{15,19}$ in energy storage applications such as batteries and supercapacitors, it has been stated that electrochemical properties of titania particles mostly depend on the size of the particles rather than the phases. To the best of authors' knowledge, there are no reports in the literature regarding the capacitance of such a mixture, and no significant differences are reported between rutile and anatase. ${ }^{7,16}$ It is also emphasized that the formation of rutile cannot result in any enhancement in the capacitance, and the maximum capacitance of rutile film is reported to be around $40 \mathrm{nF} \mathrm{cm}{ }^{-2}$, which might be considered to be negligible. ${ }^{20}$

Furthermore, it is worth pointing out that in energy storage applications, capacitive effects arising only from nanostructured $\mathrm{TiO}_{2}$ have received much less attention. ${ }^{21}$ It is possibly because the semiconducting nature of bare $\mathrm{TiO}_{2}$ limits conductivity and prevents fast electron transfer. Therefore, $\mathrm{TiO}_{2}$ is mostly considered as a conventional EDLC which only contributes a very low faradic capacitance $\left(10-70 \mu \mathrm{F} \mathrm{cm}^{-2}\right) .{ }^{22-24}$ Many approaches have been practiced to overcome the resistivity of 
titania such as carbo-thermal reduction treatment, ${ }^{25}$ the addition of electroactive species, ${ }^{18}$ etc. In a recent paper, ${ }^{26}$ we demonstrated that one-dimensional titania network, such as nanotubular architecture, exhibits unique electrical properties due to the special geometry, high aspect ratio and high surface area of titania nanotubes. This special kind of structure facilitates ion transfer inside and/or outside of the walls, especially in electrochemical applications. Therefore, many studies have been focused on the synthesis of titania with high aspect ratio, such as titania nanotubes prepared by anodic oxidation.

In the present paper, we have demonstrated that an optimal reductive treatment through a systematic anatase to rutile phase transformation can overcome the charge transfer limitation of titania nanotube layers. Various microstructural and electrochemical characterizations were conducted to investigate the crystal phase, surface morphology, electrical conductivity, and electrochemical properties of obtained titania nanotube arrays.

\section{Experimental procedure}

Self-organized $\mathrm{TiO}_{2}$ nanotube arrays (TNTA) were made via the anodic oxidation method with a two-electrode configuration, including Ti foil (99.7\% purity, Sigma) acting as the anode and platinum foil acting as the cathode, as earlier reported in our previous works. ${ }^{26,27}$ The electrolyte consisted of $0.2 \mathrm{wt} \% \mathrm{NH}_{4} \mathrm{~F}$ dissolved in a mixture of glycerol and de-ionized water $(9: 1$ in volume). The synthesis process was conducted in a thermostatic water bath to keep the temperature of the electrolyte constant. The anodization was performed under a constant voltage of $15 \mathrm{~V}$ for $17 \mathrm{~h}$. After being dried in air, samples were annealed at different temperatures of $450,500,550,600$, and $650{ }^{\circ} \mathrm{C}$ under an argon atmosphere for $5 \mathrm{~h}$ (respectively designated as TNTA $/ 450-$ TNTA $/ 650{ }^{\circ} \mathrm{C}$ ).

Field emission scanning electron microscopy (FE-SEM; JEOL JSM-7500FA), glancing angle X-ray diffraction (GAXRD; GBC MMA X-ray diffractometer with $\mathrm{Cu}-\mathrm{K} \alpha$ radiation, and $2 \theta=7^{\circ}$ ), Raman spectroscopy (LabRAM HR, Horiba Jobin Yvon SAS using a $632.8 \mathrm{~nm}$ laser), and $\mathrm{X}$-ray photoelectron spectroscopy (XPS; SPECS system with $\mathrm{Al}-\mathrm{K} \alpha$ radiation and a pass energy of $20 \mathrm{eV}$ ) methods were employed to investigate the surface morphology and microstructure of the synthesized $\mathrm{TiO}_{2}$ nanotubes.

A conventional method, including a three-electrode system in a beaker type cell at room temperature, was used for electrochemical characterization of the samples. Aligned titania nanotubes grown on a Ti substrate with $1 \mathrm{~cm}^{2}$ surface area were used directly as the working electrode. A piece of platinum foil (exposed surface of $3 \mathrm{~cm}^{2}$ ) and an $\mathrm{Ag} / \mathrm{AgCl}(\mathrm{KCl}$ saturated) electrode were used as the counter and reference electrodes, respectively. Electrochemical measurements were performed in $1 \mathrm{M} \mathrm{NaOH}$ aqueous solution. Cyclic voltammetry $(\mathrm{CV})$ and electrochemical impedance spectroscopy (EIS) measurements were carried out using a Bio-Logic VMP3 battery tester. $\mathrm{CV}$ tests were conducted over a voltage range of -0.6 to $0.3 \mathrm{~V}$ at various scan rates (from 1 to $100 \mathrm{mV} \mathrm{s}{ }^{-1}$ ). The frequency range of $10 \mathrm{kHz}$ to $10 \mathrm{mHz}$ under a bias potential of $-0.4 \mathrm{~V}$ using a $5 \mathrm{mV}$ rms sinusoidal modulation was chosen for EIS measurements. Galvanostatic chargedischarge (CD) method was applied using a battery test system
(LAND CT2001A) to calculate the capacitance and investigate the cycle life of the electrodes. CD tests of all samples was measured over a potential window range of -0.6 to $0.3 \mathrm{~V}$ at various current densities (from 33 to $333 \mathrm{~m} \mathrm{Ag}^{-1}$ ).

\section{Results and discussion}

\section{Structural characterization}

Fig. 1(a) shows the GAXRD patterns collected over $2 \theta$ range of $20^{\circ}$ to $60^{\circ}$ from titania nanotube arrays (TNTA) annealed at various temperatures under an argon (Ar) atmosphere for $5 \mathrm{~h}$. In order to reduce the effect of substrate contributions, the scanning angle $2 \theta\left(7^{\circ}\right)$ was selected to collect the maximum intensity of the major peaks of anatase $\left(2 \theta=25.17^{\circ},(101)\right)$ and rutile $\left(2 \theta=27.2^{\circ},(110)\right)$. Based on the variation of peak shapes with respect to annealing temperature, it can be concluded that the structural evolution of $\mathrm{TiO}_{2}$ nanotubes is significantly affected by the annealing temperature. Although the rutile phase appears after annealing at $450{ }^{\circ} \mathrm{C}$ under an $\mathrm{Ar}$ atmosphere, GAXRD patterns of the annealed samples clearly demonstrate that anatase is the dominant phase after annealing at this temperature. While anatase is not an equilibrium phase of $\mathrm{TiO}_{2}$, it is kinetically stabilized. Increasing the annealing temperature above $550{ }^{\circ} \mathrm{C}$ promotes the formation of the thermodynamically stable phase of $\mathrm{TiO}_{2}$ (i.e. rutile). Further increase in annealing temperature, above $650{ }^{\circ} \mathrm{C}$, results in higher transformation of anatase to rutile, leading to an almost complete rutile texture. Therefore, it can be concluded that the anatase to rutile phase transformation $(\mathrm{A} \rightarrow \mathrm{R})$ has been completed after annealing at $650{ }^{\circ} \mathrm{C}$ for $5 \mathrm{~h}$ and the resultant TNTA sample only consists of the rutile phase. The weight fraction of the rutile phase calculated from XRD patterns (eqn (1)) is plotted in Fig. 1(b).

$$
f_{\mathrm{R}}=1 /\left[1+0.8\left(I_{\mathrm{A}} / I_{\mathrm{R}}\right)\right]
$$

where $f_{\mathrm{R}}$ is the weight fraction of rutile, and $I_{\mathrm{R}}$ and $I_{\mathrm{A}}$ denote the rutile (110) and anatase (101) reflection intensities. ${ }^{28}$ The obtained curve seems to have a sigmoidal shape (growing steeper with increasing temperature), suggesting that the anatase to rutile phase transformation occurs through a nucleation and growth mechanism. ${ }^{29}$

It is well established that annealing in a neutral oxygen free environment promotes the $\mathrm{A} \rightarrow \mathrm{R}$ transformation due to the introduction of some structural defects into the $\mathrm{TiO}_{2}$ network. ${ }^{30}$ A comparison between the TNTA annealed at $550{ }^{\circ} \mathrm{C}$ in air and under argon atmospheres supports the idea that the transformation rate of the anatase to rutile phase can be much enhanced upon the introduction of a reductive atmosphere. ${ }^{26,27}$ Based on grain growth mechanisms, faceting should occur, which results in both high and low grain-boundary motilities. ${ }^{31}$ Therefore, certain crystallographically favoured grain boundaries decompose into flat facets that lie along low-energy inclinations. ${ }^{32}$ In the case of anatase, the grain boundaries are thermodynamically inclined to facet towards the rutile phase structure. In general, the Ti-O bonds of the anatase phase structure break to rearrange themselves in the rutile structure during the $\mathrm{A} \rightarrow \mathrm{R}$ phase transformation. As mentioned earlier, annealing titania in an oxygen free atmosphere results 

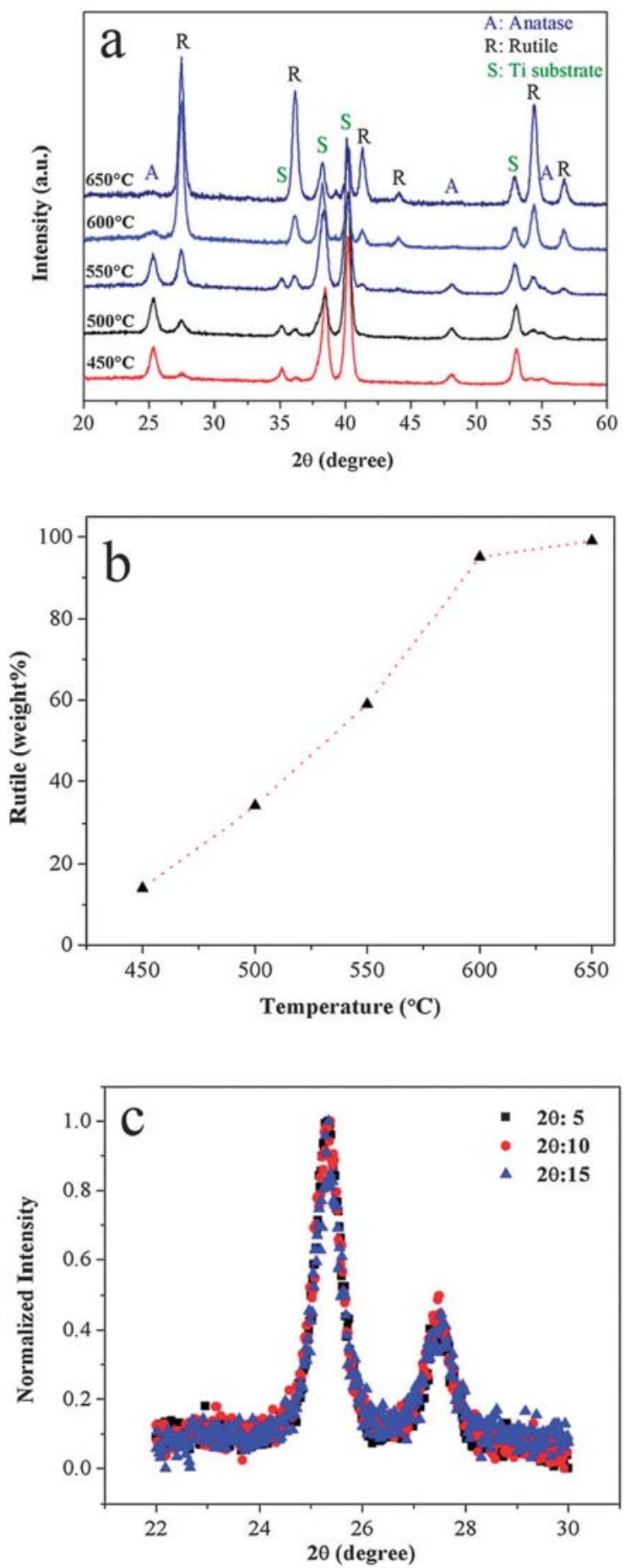

Fig. 1 (a) GAXRD patterns of the TNTA $/ 450-650{ }^{\circ} \mathrm{C}$ samples, (b) calculated weight fraction of the rutile phase in TNTA $/ 450-650{ }^{\circ} \mathrm{C}$ from GAXRD patterns, (c) overlaid XRD patterns of TNTA $/ 500{ }^{\circ} \mathrm{C}$ collected at different incident angles.

in the creation of some structural defects, such as the partial reduction of $\mathrm{Ti}^{+4}$ to $\mathrm{Ti}^{+3}$ and oxygen vacancies inside the $\mathrm{TiO}_{2}$ network. On the other hand, the existence of such a non-stoichiometric structure can reduce the activation energy of the transformation and accelerate it. ${ }^{27}$

Mor et al. ${ }^{30}$ suggested that, at any temperature range in which both anatase and rutile phases can coexist, the rutile formation occurs at the nanotube-metal interface sites, whereas the anatase crystals located on the nanotube walls cannot be transformed into the rutile phase due to the constraints imposed by the walls.

Therefore, in order to obtain a better understanding of the distribution of the polymorphic phases along nanotubes length, all samples were subjected to different X-ray incident angles (defined as the angle between the X-ray beam and the substrate plane), ranging from $5^{\circ}$ to $15^{\circ}$. Fig. 1(c) shows the overlaid normalized GAXRD patterns of TNTA $/ 500{ }^{\circ} \mathrm{C}$ collected at low incident X-ray radiation. Quite interestingly, the distribution of anatase and rutile phases was almost constant at different incident angles, suggesting an even distribution of polymorphic phases along the tubes, which might be due to the fact that the nanotubes were subjected to high dwelling time at high temperatures. The same trend was observed for all of the samples annealed at different temperatures.

Phase changes due to annealing under different conditions were fully investigated by Raman spectroscopy (Fig. 2(a)). The Raman bands located at $\sim 142,194,394,513$, and $634 \mathrm{~cm}^{-1}$ are attributed to the anatase phase, and the bands located at $\sim 141,237,447$, and $610 \mathrm{~cm}^{-1}$ are assigned to the rutile phase. ${ }^{17}$ Raman spectra serve as a further proof that increasing the annealing temperature induces the transition from the anatase to rutile phase. Our previous study ${ }^{27}$ addressed the behaviour of titania nanotubes in detail upon annealing under different atmospheres, which confirms the existence of oxygen vacancies inside self-organized $\mathrm{TiO}_{2}$ nanotubes after annealing under an argon atmosphere. Curve fitting of $\mathrm{TiO}_{2}$ Raman spectra was performed using Origin software employing a Gaussian-Lorentzian peak shape after performing a background correction. The calculated downshift values of the rutile Raman band located at $\sim 447 \mathrm{~cm}^{-1}$ for TNTA/ $500-650{ }^{\circ} \mathrm{C}$ are illustrated in Fig. 2(b). Almost the same rutile Raman downshift is observed in the present samples, which implies two facts. First, oxygen vacancies were generated due to the reduction of $\mathrm{Ti}^{+4}$ to $\mathrm{Ti}^{+3}$ at the surface of titania nanotubes. Second, comparing with the previous results for the samples annealed under an Ar atmosphere for $2 \mathrm{~h},{ }^{27}$ increasing the annealing time to $5 \mathrm{~h}$ led to the formation of lower amount of oxygen vacancies based on the lower rutile Raman downshift. In order to attain a more clear understanding of the structural evolution during the annealing process, X-ray photoelectron spectroscopy (XPS) analysis was applied.

High energy spectroscopy has played an important role in the study of electronic structures of transition metal compounds. ${ }^{33}$ Typical Ti $2 \mathrm{p}$ spectra of all samples obtained by XPS are shown in Fig. 3(a). Deconvolution and curve fitting of Ti $2 p$ spectra were performed using CasaXPS software employing a Gaussian-Lorentzian peak shape after performing a Shirley background correction. The Ti $2 p$ spectra mainly consist of four individual peaks. Two peaks located at binding energy of $\sim 464.4$ and $458.7 \mathrm{eV}$ can be assigned to the core level of $\mathrm{Ti}^{4+}$ $2 \mathrm{p}_{1 / 2}$ and $\mathrm{Ti}^{4+} 2 \mathrm{p}_{3 / 2}$, respectively. ${ }^{34-36}$ After fitting, two subpeaks, Sub-1 and Sub-2, appear at lower binding energies, which can be assigned to $\mathrm{Ti}^{3+}$ from a sub-stoichiometric oxide, $\mathrm{Ti}_{2} \mathrm{O}_{3}$. Nevertheless, no evidence of $\mathrm{Ti}_{2} \mathrm{O}_{3}$ phase can be observed in neither Raman spectra nor the XRD patterns of the samples. The $\mathrm{A}_{1 \mathrm{~g}}$ mode at $269 \mathrm{~cm}^{-1}(300 \mathrm{~K})$ is typically considered to be the main component of Raman-active modes 
(a)

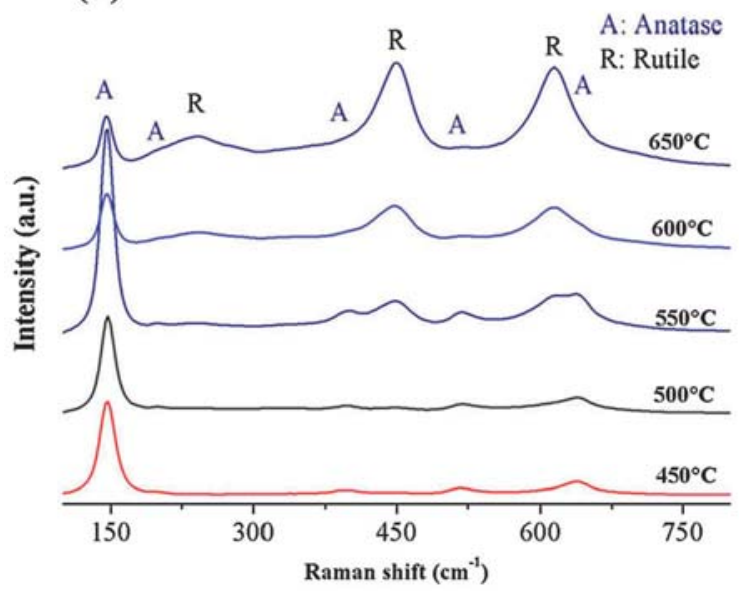

(b)

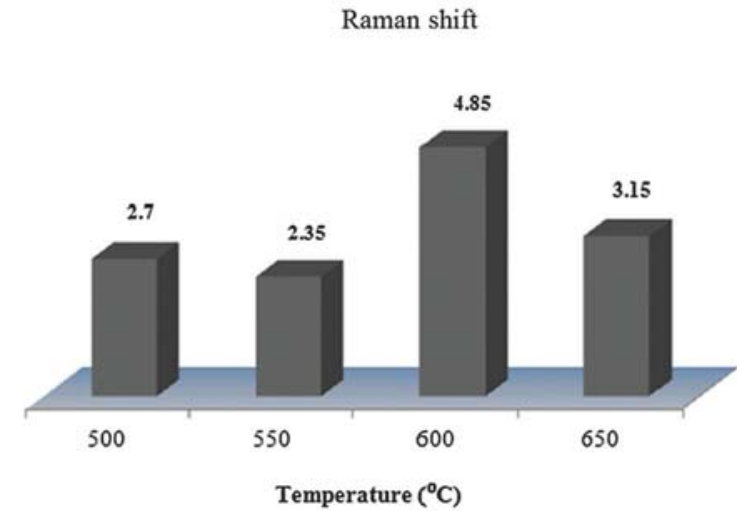

Fig. 2 (a) Raman spectra of the TNTA $/ 450-650{ }^{\circ} \mathrm{C}$ samples, (b) Raman shift of the rutile Raman band located at $447 \mathrm{~cm}^{-1}$.

of the $\mathrm{Ti}_{2} \mathrm{O}_{3}$ phase under ambient conditions. The $\mathrm{A}_{1 \mathrm{~g}}$ mode exhibits a significant frequency change (about $16 \%$ ) and a large intensity increase relative to other modes at room temperature. However, the Raman study provides no information as to the nature of the change on the surface of the tubes. These additional peaks located at $\sim 461.8$ and $456.0 \mathrm{eV}$ are therefore ascribed to $\mathrm{Ti}^{3+} 2 \mathrm{p}_{1 / 2}$ and $\mathrm{Ti}^{3+} 2 \mathrm{p}_{3 / 2}$, respectively. Fewer oxygen atoms are available in the $\mathrm{TiO}_{2}$ network due to the introduction of a reductive atmosphere, which leads to the formation of titanium interstitials $\left(\mathrm{Ti}^{3+}\right){ }^{25,33,34}$ The XPS data for Ti $2 \mathrm{p}_{1 / 2}$ and Ti $2 \mathrm{p}_{3 / 2}$ are given in Table 1 .

The enhancement of $\mathrm{Ti}^{3+}$ peaks indicates that more $\mathrm{Ti}_{2} \mathrm{O}_{3}$ is formed on the surface of $\mathrm{TiO}_{2}$ nanotubes. A simple method was applied to quantify the relative concentration of $\mathrm{Ti}^{3+}$ cations in samples:

$$
\% \mathrm{Ti}^{3+}=\left[A_{\mathrm{Ti}^{3+}} /\left(A_{\mathrm{Ti}^{3+}}+A_{\mathrm{Ti}^{4+}}\right)\right] \times 100
$$

where $A_{\mathrm{Ti}^{3+}}$ and $A_{\mathrm{Ti}^{4+}}$ denote the total areas of the peaks assigned to $\mathrm{Ti}^{3+}$ and $\mathrm{Ti}^{4+}$, respectively. The plot in Fig. 3(b) clearly presents the fact that the percentage of $\mathrm{Ti}^{3+}$ strongly depends on the annealing temperature. Therefore, it can be deduced that the most non-stoichiometric state of titania could be obtained by annealing at $650{ }^{\circ} \mathrm{C}$.

As was discussed above, annealing in a neutral and oxygen free environment is likely to result in the formation of partial oxygen vacancies in the titania network. Yet the extracted data in Fig. 3(b) demonstrate that the ratio of $\mathrm{Ti}^{3+}$ to $\mathrm{Ti}^{4+}$ increases remarkably after annealing at a temperature in excess of $550{ }^{\circ} \mathrm{C}$. Therefore, although annealing for longer periods of time leads to atomic re-construction inside the $\mathrm{TiO}_{2}$ network, resulting in a much lower density of oxygen vacancies, a higher ratio of $\mathrm{Ti}^{3+} / \mathrm{Ti}^{4+}$ can still be obtained. Based on the XPS results and XRD patterns, it seems that the amount of $\mathrm{Ti}^{3+}$ slightly decreases during the formation of the rutile phase upon annealing at $550{ }^{\circ} \mathrm{C}$, and then increases after the completion of $\mathrm{A} \rightarrow \mathrm{R}$ transformation.

Comparing the Raman and XPS spectra demonstrates that annealing the self-organized titania nanotubes in a reductive atmosphere for $5 \mathrm{~h}$ is more likely to form reduced $\mathrm{Ti}^{+3}$ cations. The enhanced heat-treatment duration could be partially responsible for the observed phenomena, while introducing an inert atmosphere at higher temperature also increases the ratio of $\mathrm{Ti}^{+3} / \mathrm{Ti}^{+4}$.

Fig. 4(a) and (b) show top view FE-SEM micrographs of TNTA $/ 450-650{ }^{\circ} \mathrm{C}$. The average wall thickness and inner diameter of the $\mathrm{TiO}_{2}$ nanotubes measured from FE-SEM images are approximately $10-15 \mathrm{~nm}$ and $25-40 \mathrm{~nm}$, respectively. A typical side view of as-prepared TNTA is shown in Fig. 4(c). The micrograph clearly shows that the as-prepared vertically aligned titania nanotubes architecture are well separated from each other. Top view FE-SEM images in moderate magnifications (Fig. 4(a)) confirm the formation of nanotubes over the surface of the $\mathrm{Ti}$ substrate in samples annealed at $450{ }^{\circ} \mathrm{C}$ to $550{ }^{\circ} \mathrm{C}$. Based on the XRD patterns, the anatase phase is the dominant phase in the TNTAs annealed at temperatures lower than $550{ }^{\circ} \mathrm{C}$. FE-SEM micrographs of these samples (Fig. $4\left(\mathrm{a}-450{ }^{\circ} \mathrm{C}\right.$ to a-550 $\left.{ }^{\circ} \mathrm{C}\right)$ ) demonstrate no detrimental effect on the ordered morphology of nanotubes after annealing. However, the top view FE-SEM images of TNTA/ $600{ }^{\circ} \mathrm{C}$ and $650{ }^{\circ} \mathrm{C}$ show some small particles besides nanotubes. It has been suggested that nanotube collapse is strongly linked to the rutile conversion. ${ }^{11}$ As it is clear in Fig. 4(b), some of the tubes start to stick together and gradually grow to form bigger particles at higher temperatures (TNTA $/ 650{ }^{\circ} \mathrm{C}$ ), which promotes the $\mathrm{A} \rightarrow \mathrm{R}$ transformation. Therefore, it can be concluded that annealing at $650{ }^{\circ} \mathrm{C}$ does not have any additional beneficial effect compared to $600{ }^{\circ} \mathrm{C}$ due to the collapse of nanotubes and results in the detachment of nanotubes from some parts of the Ti substrate. In a recent report, Hesabi et al. ${ }^{18}$ reported that the tubular structure collapses during the heat treatment process and concluded that short tubes cannot survive at high temperatures. However, our as-prepared TNTAs typically exhibit much longer lengths (on the order of $750 \mathrm{~nm}$ ). As a result, our nanotubes can retain their structure up to $600{ }^{\circ} \mathrm{C}$.

\section{Electrochemical characterization}

Cyclic voltammetry (CV) is usually the first method used to measure the performance of working electrodes in supercapacitor applications. Cyclic voltammetry tests of TNTA/450-650 ${ }^{\circ} \mathrm{C}$ 

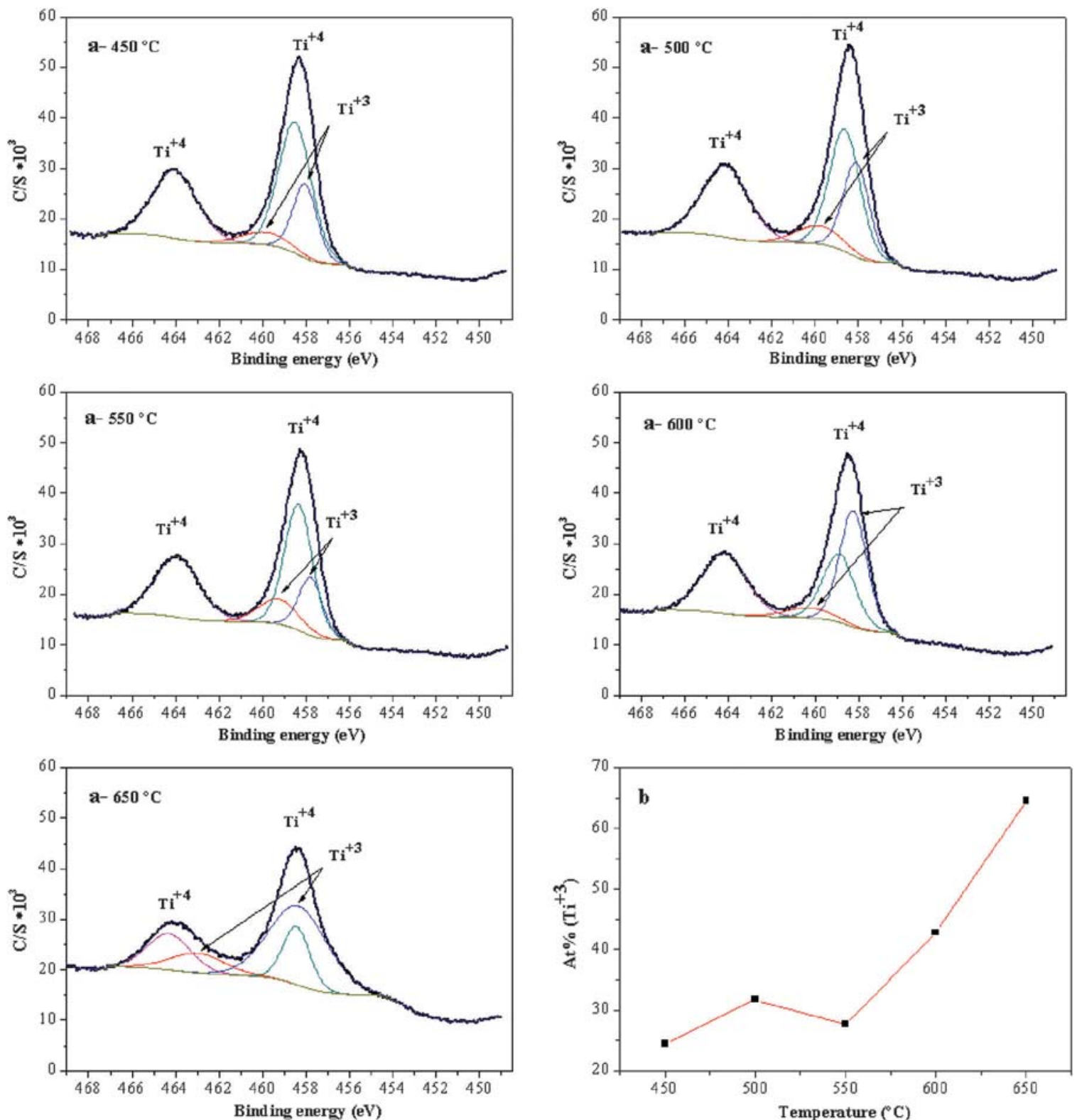

Fig. 3 (a) Experimental and fitted XPS spectra of TNTA $/ 450-650{ }^{\circ} \mathrm{C}$ and (b) calculated atomic percent of $\mathrm{Ti}^{3+}$ in titania nanotubes.

Table 1 XPS data for Ti $2 \mathrm{p}_{1 / 2}$ and Ti $2 \mathrm{p}_{3 / 2}$

\begin{tabular}{|c|c|c|c|c|c|c|c|c|c|c|c|c|c|}
\hline \multirow[b]{2}{*}{$\begin{array}{l}\text { Annealing } \\
\text { temperature } /{ }^{\circ} \mathrm{C}\end{array}$} & \multicolumn{3}{|l|}{$\underline{\mathrm{Ti}^{4+} 2 \mathrm{P}_{1 / 2}}$} & \multicolumn{3}{|l|}{$\underline{\text { Sub-1 }}$} & \multicolumn{3}{|l|}{$\underline{\mathrm{Ti}^{4+} 2 \mathrm{p}_{3 / 2}}$} & \multicolumn{3}{|l|}{$\underline{\text { Sub-2 }}$} & \multirow[b]{2}{*}{$\begin{array}{l}\text { Standard } \\
\text { deviation }\end{array}$} \\
\hline & $\begin{array}{l}\text { Binding } \\
\text { energy/eV }\end{array}$ & $\begin{array}{l}\text { Area } \\
(\%)\end{array}$ & $\begin{array}{l}\text { FWHM/ } \\
\text { eV }\end{array}$ & $\begin{array}{l}\text { Binding } \\
\text { energy/eV }\end{array}$ & $\begin{array}{l}\text { Area } \\
(\%)\end{array}$ & $\begin{array}{l}\text { FWHM/ } \\
\text { eV }\end{array}$ & $\begin{array}{l}\text { Binding } \\
\text { energy/eV }\end{array}$ & $\begin{array}{l}\text { Area } \\
(\%)\end{array}$ & $\begin{array}{l}\text { FWHM/ } \\
\text { eV }\end{array}$ & $\begin{array}{l}\text { Binding } \\
\text { energy/eV }\end{array}$ & $\begin{array}{l}\text { Area } \\
(\%)\end{array}$ & $\begin{array}{l}\text { FWHM/ } \\
\mathrm{eV}\end{array}$ & \\
\hline 450 & 464.04 & 2.41 & 31.35 & 459.86 & 2.63 & 6.20 & 458.50 & 1.77 & 44.13 & 458.04 & 1.31 & 18.32 & 0.9909 \\
\hline 500 & 464.13 & 2.46 & 31.93 & 459.81 & 2.46 & 8.12 & 458.63 & 1.65 & 36.31 & 458.11 & 1.39 & 23.64 & 0.9991 \\
\hline 550 & 463.93 & 2.37 & 31.15 & 459.26 & 2.17 & 11.64 & 458.34 & 1.52 & 41.2 & 457.79 & 1.28 & 16.01 & 0.9999 \\
\hline 600 & 464.18 & 2.41 & 31.42 & 460.28 & 2.69 & 5.72 & 458.90 & 1.74 & 25.74 & 458.26 & 1.47 & 37.12 & 0.9989 \\
\hline 650 & 463.31 & 2.32 & 17.62 & 462.99 & 2.87 & 11.96 & 458.43 & 1.45 & 17.76 & 458.34 & 3.16 & 52.67 & 0.9922 \\
\hline
\end{tabular}

were carried out at potentials between -0.6 and $0.3 \mathrm{~V}$ using $1 \mathrm{M} \mathrm{NaOH}$ aqueous electrolyte solution. The overlaid CV responses of the samples at the scan rate of $100 \mathrm{mV} \mathrm{s}^{-1}$ are shown in Fig. 5(a). $\mathrm{TiO}_{2}$ typically shows an almost rectangular cyclic voltammogram, which stands out as an indication of electrochemical double layer supercapacitors. The specific capacitance $\left(C_{\mathrm{s}}\right)$ of the electrodes was calculated from the following equation (eqn (3)):

$$
C_{\mathrm{s}}=C /[S(/ m)]=I /[(\mathrm{d} v / \mathrm{d} t) \times S(/ m)]
$$

where $I$ is the charge-discharge current, $\mathrm{d} V / \mathrm{d} t$ is the scan rate, and $S(/ m)$ is the surface area of the working 

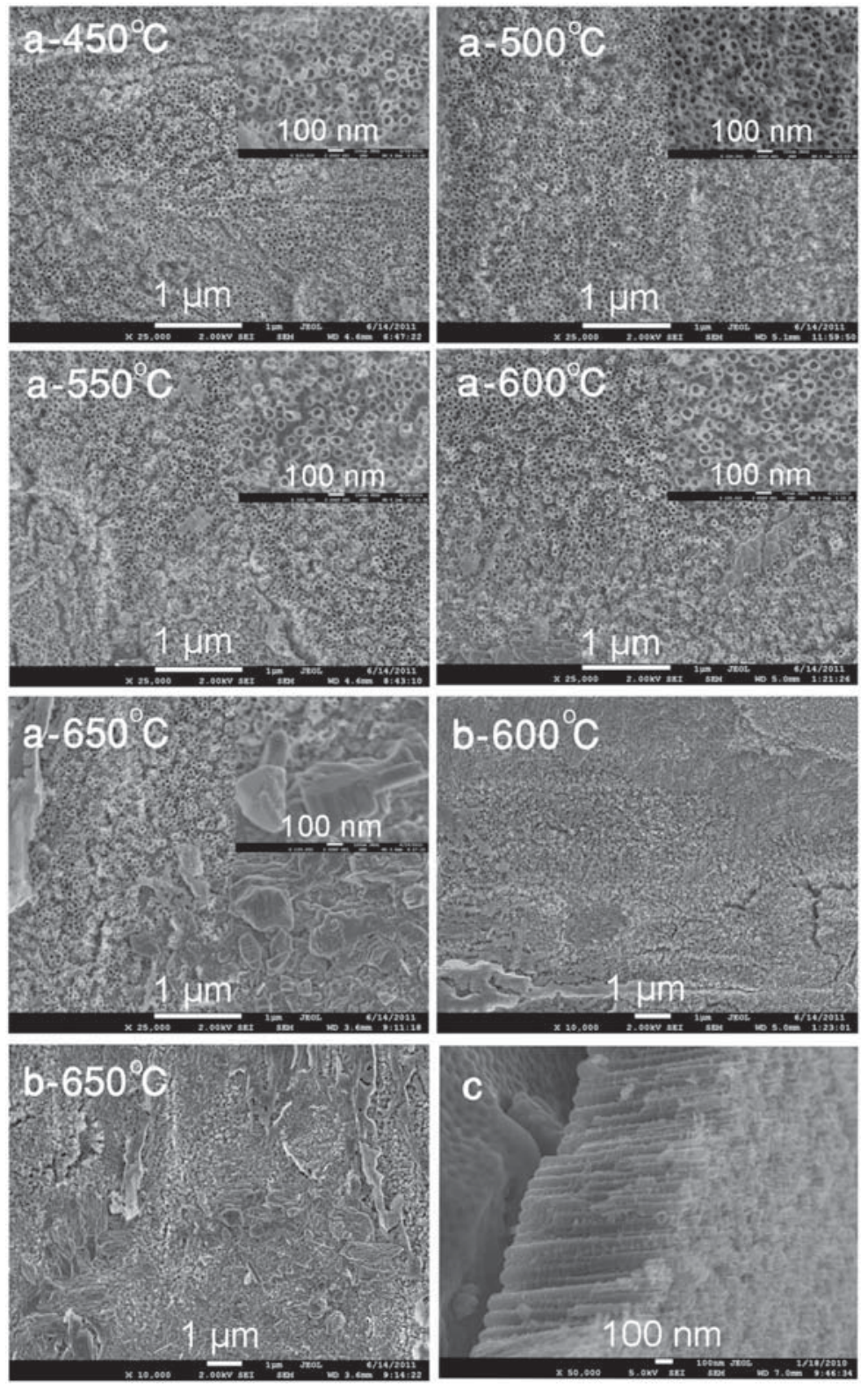

Fig. 4 (a) Top view FE-SEM micrographs of TNTA, with higher magnification as inset, (b) low magnification top view of samples annealed at $600{ }^{\circ} \mathrm{C}$ and $650{ }^{\circ} \mathrm{C}$, and (c) a typical side view of as-prepared TNTA.

electrode (/mass of active material). The specific capacitance of TNTAs was calculated based on both surface area and the mass of the active material. The cyclic voltammograms demonstrate a significant increase in capacitance with increasing annealing temperature up to $600{ }^{\circ} \mathrm{C}$. However, the decrease in the area under the rectangular curve for the sample annealed at $650{ }^{\circ} \mathrm{C}$ reflects a drop in capacitance due to heating at this temperature. The calculated specific capacitance of samples annealed at $600{ }^{\circ} \mathrm{C}$ is plotted against the scan rate in Fig. 5(b). The highest value of specific capacitance was recorded to be $2.6 \mathrm{mF} \mathrm{cm}^{-2}\left(19.2 \pm 2.5 \mathrm{Fg}^{-1}\right)$ at $1 \mathrm{mV} \mathrm{s}^{-1}$. This value is far higher than the values already reported in the literature for $\mathrm{TiO}_{2}$ $\left(10-120 \mu \mathrm{F} \mathrm{cm}{ }^{-2}\right)^{21-23,37}$ and other conventional double layer capacitors $\left(12.6 \mathrm{Fg}^{-1}\right) .{ }^{4}$ The capacitance values decreased with increasing scan rate, as is usually expected due to the diffusion limitations in the nanotube channels. ${ }^{3,21}$
In our previous work, ${ }^{26}$ we found that titania nanotube channels prepared by anodic oxidation could enhance the capacitance properties of $\mathrm{TiO}_{2}$ through providing a direct pathway for electron transfer. In addition, the oxygen vacancies created inside the structures greatly increase the capacitance of $\mathrm{TiO}_{2}$ nanotubes supercapacitors due to increase in the $\mathrm{TiO}_{2}$ conductivity. ${ }^{27}$ In the present work, however, increased specific capacitance could be attributed to the partially reduced valence states created at the surface of the titania nanotubes. The enhanced capacitance might also be due to the presence of other defects formed during annealing in a reductive atmosphere, such as titanium interstitials. As discussed above, the higher the temperature, the higher the ratio of $\mathrm{Ti}^{3+} / \mathrm{Ti}^{4+}$ would be. Moreover, changing the electrical properties of oxides through changing the reduction conditions is an already wellestablished technique in the literature, i.e., annealing $\mathrm{TiO}_{2}$ in 

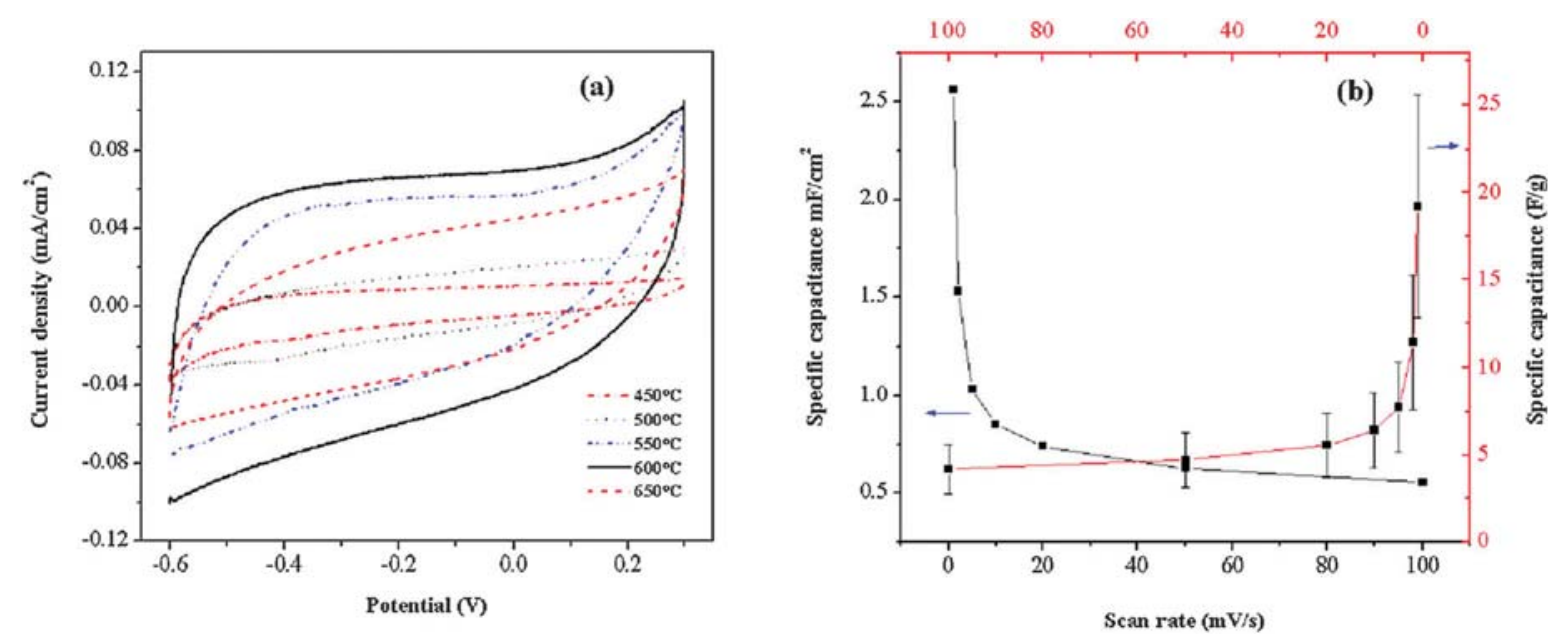

Fig. 5 (a) Comparative $\mathrm{CV}$ tests of TNTA $/ 450-650{ }^{\circ} \mathrm{C}$ at a scan rate of $100 \mathrm{mV} \mathrm{s}{ }^{-1}$, and (b) variation of specific capacitance with scan rate of TNTA $/ 600{ }^{\circ} \mathrm{C}$, in $1 \mathrm{M} \mathrm{NaOH}$ and $\mathrm{Ag} / \mathrm{AgCl}(\mathrm{KCl}$ saturated) as the reference electrode.

an inert atmosphere provides higher conductivity values due to the conversion of $\mathrm{Ti}^{4+}$ to $\mathrm{Ti}^{3+}$. Therefore, obtaining such a structure typically leads to higher ionic transfer during charge and discharge processes, and consequently results in higher capacitance values. However, it seems that there is an optimal temperature above which the capacitance cannot be increased, possibly due to either structural collapse or the complete conversion of anatase to rutile. These processes are linked together and result in the loss of the charge-carrying capacity within the structure.

According to the literature, in basic and neutral media, titania immediately forms a condensate with the addition of water and subsequently forms an amorphous $\mathrm{TiO}_{2}$ surface layer after anodic treatment. ${ }^{30,36}$ This fast condensation under neutral conditions leads to arbitrary bondings, resulting in a strongly condensed but poorly defined structure. ${ }^{38}$ Even the addition of $\mathrm{NH}_{3}$ cannot organize the structure into a crystalline structure mainly because the addition of bases result in very fast precipitation of $\mathrm{TiO}_{2}$ and there is not enough time for crystallization to take place. Therefore, anatase can only be formed upon calcination. In terms of electrical conductivity, anatase is much more conductive than amorphous $\mathrm{TiO}_{2}$, and the presence of rutile may lead to a decrease in electrical conductivity. ${ }^{11,39}$ However, the formation of rutile can result in the consumption of $\mathrm{Ti}^{4+}$ and the simultaneous increase of $\mathrm{Ti}^{3+} / \mathrm{Ti}^{4+}$ within the $\mathrm{TiO}_{2}$ network.

Fig. 6(a) presents the overlaid charge-discharge curves of TNTA $/ 450-650{ }^{\circ} \mathrm{C}$ at the current density of $10 \mu \mathrm{A} \mathrm{cm} \mathrm{c}^{-2}$ $\left(66 \mathrm{~m} \mathrm{Ag}^{-1}\right.$ ) over the same potential window used in the $\mathrm{CV}$ tests. The specific capacitance was calculated using the following equation:

$$
C_{\mathrm{s}}=[I \times \Delta t] /[S(/ m) \times \Delta V]
$$

where $I$ is the discharge current, $\Delta t$ is the discharge time, $S$ is the apparent surface area ( $m$ is the mass of the active material), and $\Delta V$ is the potential window. The average calculated specific capacitance for the working electrodes annealed at different temperatures of $450,500,550,600$, and $650{ }^{\circ} \mathrm{C}$ was recorded to be $1.1,1.9,2.8,7.6$, and $7.1 \mathrm{Fg}^{-1}$ at a current density of $5 \mu \mathrm{A} \mathrm{cm}^{-2}\left(33 \mathrm{~m} \mathrm{Ag}^{-1}\right)$, respectively. The same electrochemical
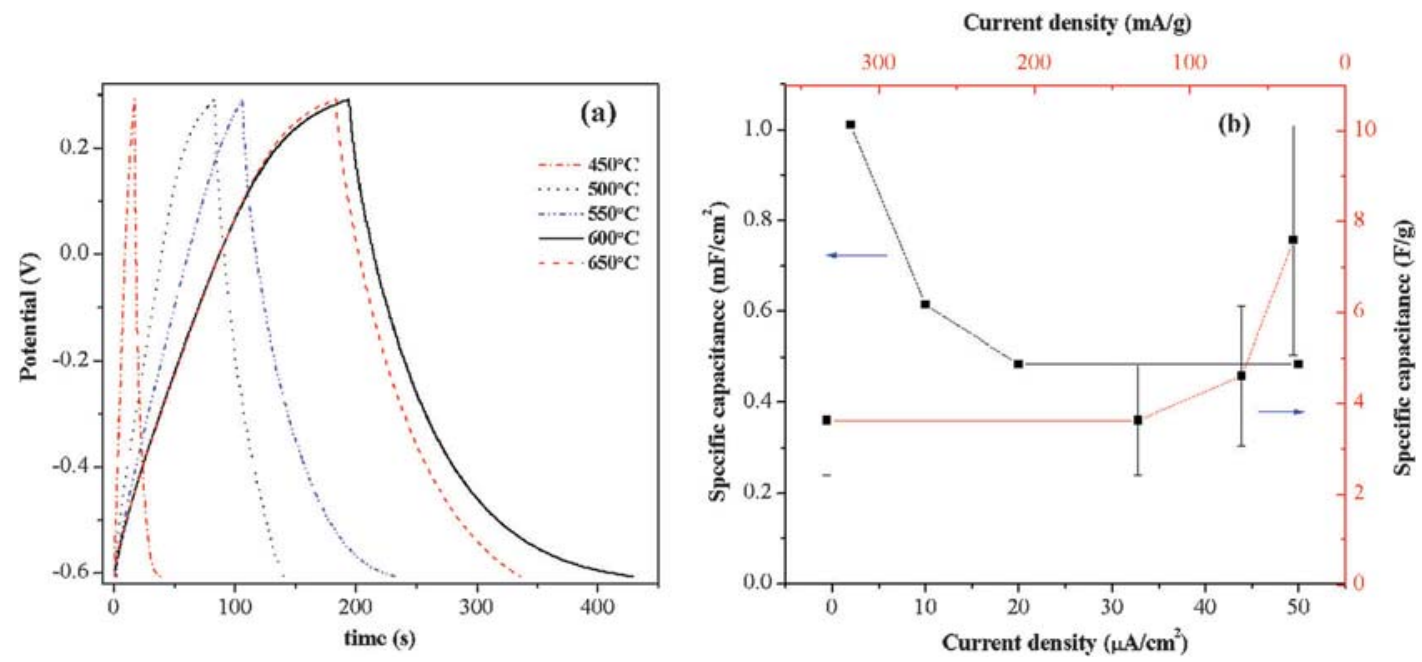

Fig. 6 (a) Comparative charge-discharge curves of TNTA $/ 450-650{ }^{\circ} \mathrm{C}$ at a current density of $10 \mu \mathrm{A} \mathrm{cm}^{-2}(66 \mathrm{~m} \mathrm{Ag}$ ), and (b) specific capacitance at different current densities of TNTA $/ 600{ }^{\circ} \mathrm{C}$, in $1 \mathrm{M} \mathrm{NaOH}$ and $\mathrm{Ag} / \mathrm{AgCl}(\mathrm{KCl}$ saturated) as the reference electrode. 
capacitance reduction trend in TNTA $/ 650{ }^{\circ} \mathrm{C}$ can be attributed to the partial collapse of the nanotube structure.

The variation of average specific capacitance with current density of TNTA $/ 600{ }^{\circ} \mathrm{C}$ is plotted in Fig. $6(\mathrm{~b})$. The highest capacitance of this sample at a current density of $33 \mathrm{~m} \mathrm{Ag}^{-1}$ is recorded to be $7.6 \mathrm{Fg}^{-1}$ while it drops to $3.6 \mathrm{Fg}^{-1}$ at the current density of $333 \mathrm{~m} \mathrm{Ag}^{-1}$. These results are in good agreement with those calculated using CV tests. A sharp decrease in specific capacitance is observed at low current densities, while an approximately stable capacitance was obtained at higher current densities, indicating good power capability of the electrode. ${ }^{3}$

A common linear relationship between voltage and the charge-discharge time curves is expected from an ideal double layer capacitor. In addition, based on the literature, $\mathrm{TiO}_{2}$ only contributes a very low non-faradic capacitance and almost no faradic capacitance..$^{2,27,40}$ However, the nanotube layers studied in this work were exposed to an inert atmosphere. It is clear in Fig. 6(a) that there is a deviation from the linear curve in the charge-discharge process, confirming that the pseudocapacitance contribution could also be involved. The authors propose that this non-linear curve could be attributed to the reduction of $\mathrm{Ti}^{4+}$ to $\mathrm{Ti}^{3+}$ on the surface of the nanotubes, which could not be detected by $\mathrm{CV}$ tests. Therefore, it is safe to assume that optimally introduced defects within titania nanotubes during the annealing process would result in a great increase in the capacitance due to a faradic reaction.

The long term cycling behaviour is one of the essential parameters in evaluating the performance of working electrodes in supercapacitor applications. The specific capacitance of the samples annealed in the temperature range of $450-650{ }^{\circ} \mathrm{C}$ at a current density of $10 \mu \mathrm{A} \mathrm{cm}{ }^{-2}\left(66 \mathrm{~m} \mathrm{Fg}^{-1}\right)$ is presented as a function of cycle number in Fig. 7. It shows that samples annealed at $450{ }^{\circ} \mathrm{C}$ and $650{ }^{\circ} \mathrm{C}$ exhibit excellent cycling performance with nearly $100 \%$ retention of capacitance up to 1000 charge-discharge cycles. A slight increase is observed in the specific capacitance of TNTA $/ 600{ }^{\circ} \mathrm{C}$ with increasing cycle number, which might be due to the activation of more non-stoichiometric states of titanium dioxide during chargedischarge processes, contributing to the enhancement of the

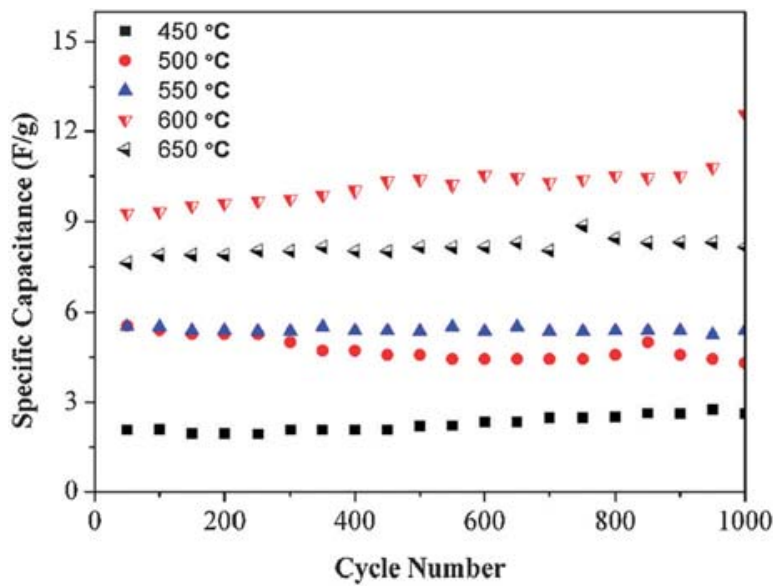

Fig. 7 Cyclic performance of TNTA $/ 450-650{ }^{\circ} \mathrm{C}$ electrodes at a current density of $10 \mu \mathrm{A} \mathrm{cm}^{-2}\left(66 \mathrm{~m} \mathrm{Fg}^{-1}\right)$. specific capacitance. Besides, as is obvious, there is a slight decrease in the capacitance of the sample annealed at $500{ }^{\circ} \mathrm{C}$ and $550{ }^{\circ} \mathrm{C}$, i.e., the specific capacitance values remain at around $77 \%$ and $97 \%$ of the original values up to 1000 cycles, respectively. The decay is likely due to the reductive states introduced in the heating regime. As was proposed earlier, there is a competition between the formation of the reduced state of $\mathrm{Ti}^{3+}$ and the formation of rutile at these two temperatures, which might have compensated the non-stoichiometric state of $\mathrm{TiO}_{2}$ and resulted in lower defects inside the tubes.

Electrochemical impedance spectroscopy (EIS) is a powerful technique widely used to study porous electrodes. It gives a good understanding regarding the internal resistance of the electrode material and the resistance between the electrode and the electrolyte. ${ }^{11,41}$ Fig. 8(a) compares the Nyquist plots of the 5 working electrodes, with EIS carried out and analysed in the frequency range of $10 \mathrm{kHz}$ to $10 \mathrm{mHz}$ at a constant potential of $-0.4 \mathrm{~V}$ and a sinusoidal perturbation of $5 \mathrm{mV}$. The high frequency region of the spectra is shown as the inset. The Nyquist plot of the sample annealed at $600{ }^{\circ} \mathrm{C}$ exhibits a much lower impedance value than the samples annealed under other conditions. To gain a better understanding of the process taking place on the electrode surface, the Nyquist plot, Bode plot, and proposed equivalent circuit $\left(R_{1}+\mathrm{CPE}_{1} / R_{2}+\right.$ $\mathrm{CPE}_{2} / R_{3}$ ) obtained from fitting of the EIS experimental data of TNTA $/ 600{ }^{\circ} \mathrm{C}$ are given in Fig. 8(b-d). The semicircle characteristic at high frequencies in the corresponding Nyquist plots reveals the charge transfer resistance $\left(R_{\mathrm{CT}}\right)$ between the electrode and electrolyte. ${ }^{12,42}$ The diameter of $R_{\mathrm{CT}}$ semicircle gives an approximate value of the electrode resistance, which is closely related to the surface area and conductivity of the active material. ${ }^{43}$ As is vividly shown in the inset of Fig. 8(a), titania nanotubes subjected to heat-treatment at $600{ }^{\circ} \mathrm{C}$ showed much lower charge transfer resistance and consequently, higher conductivity. These results are in good agreement with previous results obtained from other electrochemical techniques. At low frequencies, a pure supercapacitor electrode usually exhibits an almost vertical line on the Nyquist plot and a phase angle close to $90^{\circ}$ on the Bode plot. ${ }^{3}$ However, as is shown in Fig. 8(b) and (c), the slope on the Nyquist plot and the phase angle deviate from a perfect vertical line and $90^{\circ}$, which is due to the pseudocapacitance effects from the non-stoichiometric nanostructure introduced by the annealing process. Therefore, the purely capacitive element $\left(C_{\mathrm{dI}}\right)$ should be replaced by a constant phase element (CPE) catering for the pseudocapacitance behaviour and representing the capacitance of the working electrode (Fig. 8(d)).

The impedance results for a solid electrode/electrolyte interface often reveal a frequency dispersion that cannot be described by simple elements. The frequency dispersion is generally attributed to a "capacitance dispersion" expressed in terms of a constant-phase element. Different origins of the capacitance distribution have been discussed in the literature, including distributed surface reactivity, roughness, electrode porosity, and so on. Different equations have been proposed to estimate the impedance of the CPE. ${ }^{3,41,44}$ The CPE parameter is defined as $1 / Q^{\alpha}$ for capacitance dispersion, where the exponent $\alpha$ arises from the slope of $\log Z v s . \log f$. The value of $\alpha$ varies between -1 and 1 . When $\alpha=0$, the CPE represents a pure resistor. 

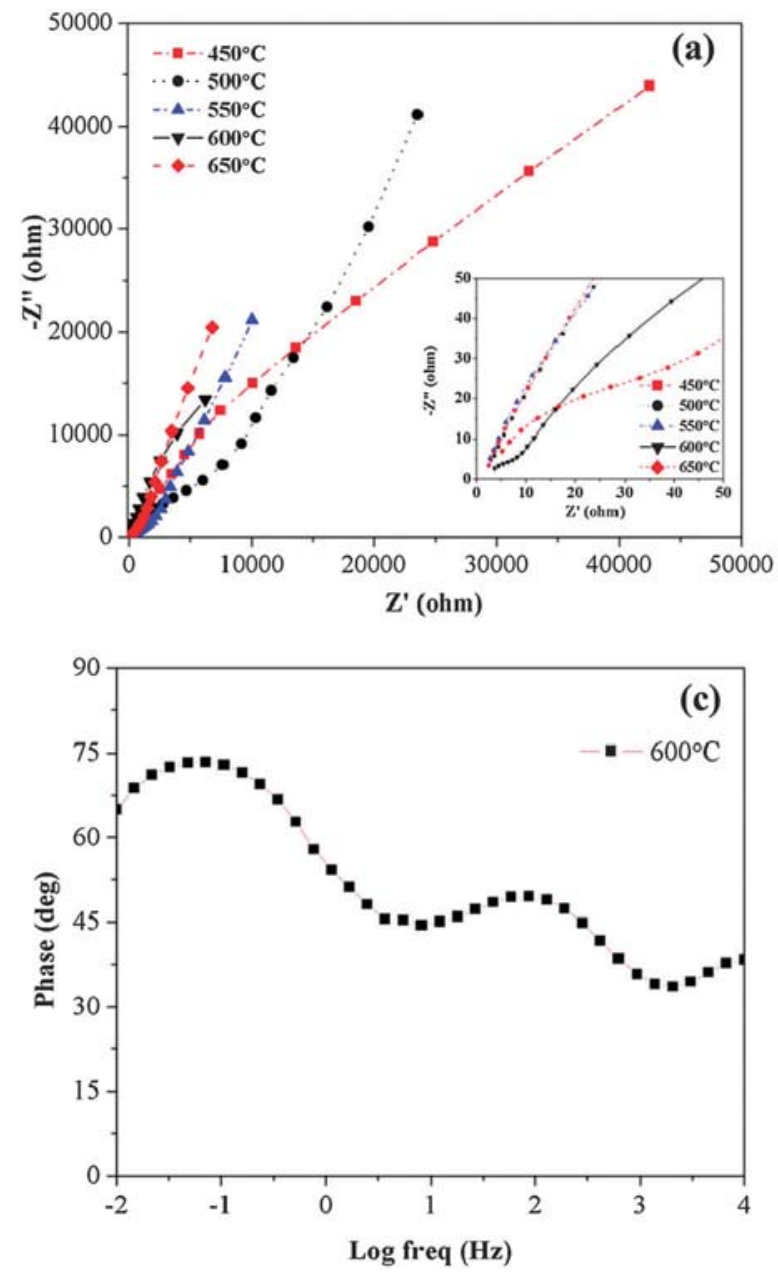

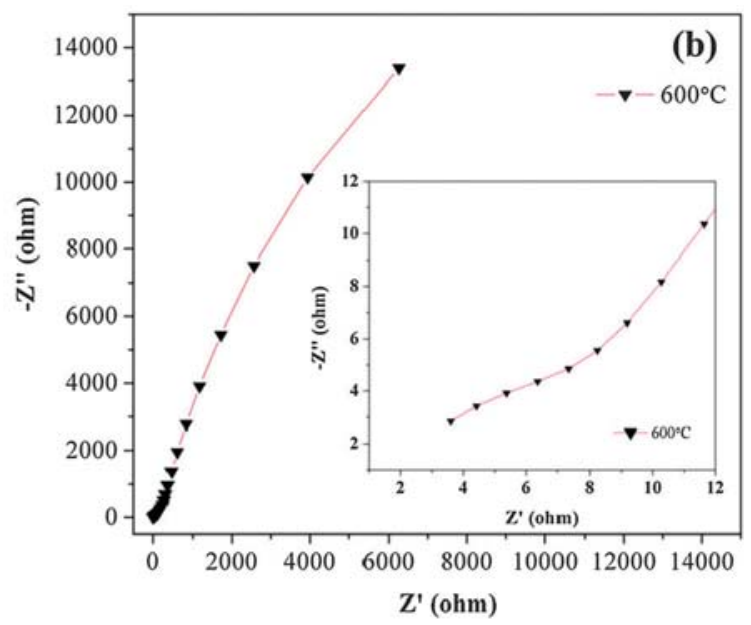

(d)

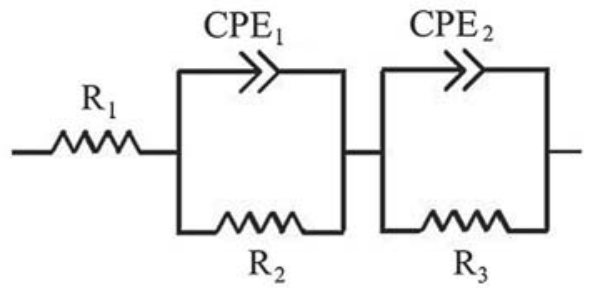

Fig. 8 (a) Comparative Nyquist plots of TNTA $/ 450-650{ }^{\circ} \mathrm{C}$ and (b) Nyquist plot for TNTA $/ 600{ }^{\circ} \mathrm{C}$, with the inset showing an enlargement of the high frequency region; (c) Bode plot for TNTA $/ 600{ }^{\circ} \mathrm{C}$, and (d) equivalent circuit of TNTA/ $600{ }^{\circ} \mathrm{C}$ at a constant potential of $-0.4 \mathrm{~V}$.

At $\alpha=1$ it represents a pure capacitor and $\alpha=-1$ it represents an inductor. At $\alpha=0.5$, the CPE corresponds to Warburg impedance $\left(Z_{\mathrm{W}}\right)$. Two CPE elements were defined to introduce the time constants needed to model the behaviour. ${ }^{3,18,41}$

$R_{1}, R_{2}$, and $R_{3}$ represent the solution resistance, the resistance of the TNTA electrode, and the charge transfer resistance through the electrode, respectively. ${ }^{11}$ The values of the fitting elements from the randomized method circuit used by Bio-Logic VMP3 are also summarized in Table 2. The proposed equivalent circuit for the TNTA $/ 600{ }^{\circ} \mathrm{C}$ electrode can be compared with that of titania nanotubes annealed in argon and nitrogen (TNT/Ar and TNT/ $\left.\mathrm{N}_{2}\right) .{ }^{11}$ The resistance of the electrode/electrolyte interface $\left(R_{2}=R_{\mathrm{CT}}\right)$ and the resistance of charge transfer through the active material $\left(R_{3}\right)$,

Table 2 Equivalent circuit parameters for TNTA $/ 600{ }^{\circ} \mathrm{C}$

\begin{tabular}{lll}
\hline Parameter & Value & Deviation \\
\hline$R_{1} / \Omega$ & 2.134 & 0.5627 \\
$\mathrm{CPE}_{1} / \mathrm{m} \mathrm{F} \mathrm{s}^{(\alpha-1)}$ & 0.7506 & $2.919 \times 10^{-6}$ \\
$\alpha_{1}$ & 0.9119 & 0.5044 \\
$R_{2} / \Omega$ & 50924 & 247.6 \\
$\mathrm{CPE}_{2} / \mathrm{m} \mathrm{F} \mathrm{s}^{(\alpha-1)}$ & 0.9518 & $39.88 \times 10^{-6}$ \\
$\alpha_{2}$ & 0.536 & 0.5107 \\
$R_{3} / \Omega$ & 313.5 & 6.549 \\
\hline
\end{tabular}

determined by the fitting of the experimental data, were found to be $0.5 \times 10^{5} \Omega$ and $313.5 \Omega$, which are 13.5 and 1200 orders of magnitudes less, respectively, than what is reported in ref. 11. Owing to the annealing of the working electrodes under optimal conditions, a partially reduced $\mathrm{TiO}_{2}$ network can lead to an extraordinary improvement of electrical conductivity and subsequent enhancement of charge propagation through the system. ${ }^{16}$ The value of the $\alpha_{1}$ parameter is very close to 1 , which denotes a pure capacitor, implying highly capacitive behaviour by the electrode. However, the deviation of the $\alpha_{2}$ value from the Warburg resistance (0.5) demonstrates a diffusion based resistance, further implying pseudocapacitive behaviour of the system.

\section{Conclusions}

In conclusion, upon annealing self-organized $\mathrm{TiO}_{2}$ nanotubes under optimal conditions, we achieved the highest reported capacitance values for an EDLC system. This process was carried out without losing the ordered nanotubular structure, while creating a high amount of defects inside the $\mathrm{TiO}_{2}$ structure at the same time. Such a non-stoichiometric state of $\mathrm{TiO}_{2}$ showed extraordinary enhancement in terms of electrochemical properties. Galvanostatic charge-discharge and EIS 
tests of the resultant electrode confirmed the contribution of the pseudocapacitance of the titania nanotube arrays and huge enhancement in ion transfer within the titania nanotube arrays. The results presented here demonstrate that titania nanotubes mostly composed of the rutile phase exhibit higher conductivity and lower charge transfer limitations, which is mainly attributed to the conversion of $\mathrm{Ti}^{+4}$ into $\mathrm{Ti}^{+3}$ through the formation of the rutile phase. In summary, the promising properties of the materials presented here are potentially applicable in many specialised technical applications, including electrical storage devices, as demonstrated.

\section{Acknowledgements}

The authors thank Dr Tania Silver for critical reading of the manuscript. Also, financial support from the University of Wollongong and the Australian Research Council (ARC, grant No. DP1093952) is acknowledged.

\section{Notes and references}

1 J. Chmiola, C. Largeot, P.-L. Taberna, P. Simon and Y. Gogotsi, Science, 2010, 328, 480-483.

2 Y. Zhu, S. Murali, M. D. Stoller, K. J. Ganesh, W. Cai, P. J. Ferreira, A. Pirkle, R. M. Wallace, K. A. Cychosz, M. Thommes, D. Su, E. A. Stach and R. S. Ruoff, Science, 2011, 332, 1537-1541.

3 S. H. Aboutalebi, A. T. Chidembo, M. Salari, K. Konstantinov, D. Wexler, H. K. Liu and S. X. Dou, Energy Environ. Sci., 2011, 4, $1855-1865$.

4 G. Zheng, L. Hu, H. Wu, X. Xie and Y. Cui, Energy Environ. Sci., 2011, 4, 3368-3373.

5 J. Chmiola, G. Yushin, Y. Gogotsi, C. Portet, P. Simon and P. L. Taberna, Science, 2006, 313, 1760-1763.

6 T. Brezesinski, J. Wang, J. Polleux, B. Dunn and S. H. Tolbert, J. Am. Chem. Soc., 2009, 131, 1802-1809.

7 D. Dambournet, I. Belharouak and K. Amine, Chem. Mater., 2009, 22, 1173-1179.

8 M. Kalbacova, J. M. Macak, F. Schmidt-Stein, C. T. Mierke and P. Schmuki, Phys. Status Solidi RRL, 2008, 2, 194-196.

9 C. Lee, C. Hong, H. Kim, J. Kang and H. M. Zheng, Photochem. Photobiol., 2010, 86, 981-989.

10 P. Thevenot, J. Cho, D. Wavhal, R. B. Timmons and L. Tang, Nanomedicine (Philadelphia, PA, U. S.), 2008, 4, 226-236.

11 P. Xiao, D. Liu, B. B. Garcia, S. Sepehri, Y. Zhang and G. Cao, Sens. Actuators, B, 2008, 134, 367-372.

12 Y. Xie, L. Zhou and J. Lu, J. Mater. Sci., 2009, 44, 2907-2915.

13 R. Vogel, P. Meredith, I. Kartini, M. Harvey, J. D. Riches, A. Bishop, N. Heckenberg, M. Trau and H. Rubinsztein-Dunlop, ChemPhysChem, 2003, 4, 595-603.

14 P. Xiao, B. B. Garcia, Q. Guo, D. Liu and G. Cao, Electrochem. Commun., 2007, 9, 2441-2447.
15 G. Li, C. P. Richter, R. L. Milot, L. Cai, C. A. Schmuttenmaer, R. H. Crabtree, G. W. Brudvig and V. S. Batista, Dalton Trans., 2009, 45, 10078-10085.

16 M. Koelsch, S. Cassaignon, C. Ta Thanh Minh, J. F. Guillemoles and J. P. Jolivet, Thin Solid Films, 2004, 451-452, 86-92.

17 M. Rezaee, S. M. Mousavi Khoie and K. H. Liu, CrystEngComm, 2011, 13, 5055-5061.

18 Z. R. Hesabi, N. K. Allam, K. Dahmen, H. Garmestani and M. A. El-Sayed, ACS Appl. Mater. Interfaces, 2011, 3, 952-955.

19 H. Nakajima, T. Mori, Q. Shen and T. Toyoda, Chem. Phys. Lett., 2005, 409, 81-84.

20 M. Yamazaki and H. Nozaki, J. Phys. Chem., 1971, 75, 1279-1283.

21 J. Wang, J. Polleux, J. Lim and B. Dunn, J. Phys. Chem. C, 2007, 111, 14925-14931.

22 Y. Xie, L. Zhou, C. Huang, H. Huang and J. Lu, Electrochim. Acta, 2008, 53, 3643-3649.

23 B. E. Conway and W. G. Pell, J. Solid State Electrochem., 2003, 7, 637-644.

24 J. R. Miller, R. A. Outlaw and B. C. Holloway, Science, 2010, 329, 1637-1639.

25 R. Hahn, F. Schmidt-Stein, J. Salonen, S. Thiemann, Y. Song, J. Kunze, V.-P. Lehto and P. Schmuki, Angew. Chem., Int. Ed., 2009, 121, 7372-7375.

26 M. Salari, S. H. Aboutalebi, K. Konstantinov and H. K. Liu, Phys. Chem. Chem. Phys., 2011, 13, 5038-5041.

27 M. Salari, K. Konstantinov and H. K. Liu, J. Mater. Chem., 2011, 21, 5128-5133.

28 M. Salari, M. Rezaee, S. P. H. Marashi and S. H. Aboutalebi, Powder Technol., 2009, 192, 54-57.

29 R. Abbaschian, L. Abbaschian and R. E. Reed-Hill, Physical Metallurgy Principles, Cengage Learning, 2008.

30 G. K. Mor, O. K. Varghese, M. Paulose and C. A. Grimes, Adv. Funct. Mater., 2005, 15, 1291-1296.

31 Z. X. Wu, Y. W. Zhang and D. J. Srolovitz, Acta Mater., 2009, 57, 4278-4287.

32 E. A. Holm and S. M. Foiles, Science, 2010, 328, 1138-1141.

33 T. Uozumi, K. Okada, A. Kotani, Y. Tbzuka and S. Shin, J. Phys. Soc. Jpn., 1996, 65, 1150-1153.

34 J.-C. Hsu, P. W. Wang and C.-C. Lee, Appl. Opt., 2006, 45, 4303-4309.

35 U. Diebold and T. Madey, Surf. Sci. Spectra, 1996, 4, 227-231.

36 Y.-L. Chung, D.-S. Gan, K.-L. Ou and S.-Y. Chiou, J. Electrochem. Soc., 2011, 158, C319-C324.

37 J. Lee, J. Choi, J. Lee, S. K. Choi and H. D. Chun, Nanotechnology, 2005, 16, 1449.

38 E. Beyers, P. Cool and E. F. Vansant, J. Phys. Chem. B, 2005, 109, 10081-10086.

39 H.-T. Fang, M. Liu, D. W. Wang, T. Sun, D. S. Guan, F. Li, J. Zhou, T. K. Sham and H. M. Cheng, Nanotechnology, 2009, 20, 225701

40 B. E. Conway, Electrochemical Supercapacitors, Kluwer Academic Publishers, New York, 1999.

41 J.-B. Jorcin, M. E. Orazem, N. Pébère and B. Tribollet, Electrochim. Acta, 2006, 51, 1473-1479.

42 C.-M. Chuang, C.-W. Huang, H. Teng and J.-M. Ting, J. Electrochem. Soc., 2010, 157, K113-K117.

43 T. C. Girija and M. V. Sangaranarayanan, J. Power Sources, 2006, 159, 1519-1526.

44 J. Bisquert, G. Garcia-Belmonte, P. Bueno, E. Longo and L. O. S. Bulhões, J. Electroanal. Chem., 1998, 452, 229-234. 